\title{
The shorthand publications of Sir William Richard Gowers
}

\author{
Kenneth L. Tyler, MD; Dorothy Roberts; and H. Richard Tyler, MD
}

\begin{abstract}
Article abstract-Objective: To examine the shorthand publications of Sir William Richard Gowers. Background: Gowers developed an almost obsessional interest in Pitman shorthand. During the later part of his active career (1894-1910), the bulk of his professional writing, comprising nearly 100 articles, was printed entirely in Pitman shorthand in the Phonographic Record of Clinical Teaching and Medical Science. The obscurity and rarity of this periodical, and the increasingly arcane nature of Pitman shorthand, has left the bulk of these articles "buried in obscurity and locked up in code" (M. Critchley, 1949). Design/Methods: A complete set of Gowers' shorthand publications as listed in his standard bibliography was compiled. Transcription of the Pitman shorthand outlines was performed by a qualified Pitman shorthand transcriber and verified using the contemporaneous Phonographic Outlines of Medical Terms (1902) as an authoritative guide. Results: The first transcription of Gowers' shorthand publications has now been completed. The history of Gowers' interest in shorthand and his efforts to proselytize the medical profession is reviewed. Selected excerpts are presented from his shorthand articles, which include papers devoted to problems in practical diagnosis, notes on clinical teaching, and the shorthand transcriptions of his lectures at Queen Square and at University College Hospital on such diverse subjects as myelitis, neurosyphilis, polio, muscular dystrophy, tumors, vascular disease, epilepsy, and the nervous system in old age. Conclusions: The previously unpublished transcriptions of his shorthand articles represent a major and previously inaccessible part of Gowers' neurologic opus. These articles exemplify Gowers as a practicing neurologist and teacher, and significantly expand our insights into one of neurology's most significant and influential figures.
\end{abstract}

NEUROLOGY 2000;55:289-293

Sir William Richard Gowers (1845-1915) is one of the epochal figures in the history of neurology. ${ }^{1} \mathrm{He}$ made seminal contributions to our understanding of muscle diseases, epilepsy, and migraine, and was largely responsible for introducing the ophthalmoscope as an essential tool in the neurologic examination. He wrote the most universally acclaimed textbook of neurology that has ever been produced. ${ }^{2}$ His clinical acumen was legendary, and his approach to patients epitomized the Queen Square tradition of neurology and helped define the modern neurologic examination.

Little is known about one of the most significant and unusual aspects of Gowers' career. He developed an obsessional interest in shorthand ("phonography"). ${ }^{1,3}$ Gowers kept both a personal diary and clinical casebooks in Pitman shorthand. He established the Society of Medical Phonographers, a group devoted to the application of shorthand to medical practice. Between 1894 and 1912, this society published a journal printed almost entirely in shorthand, entitled the Phonographic Record of Clinical
Teaching and Medical Science (PRCT), of which Gowers was the founding editor. Into this obscure publication Gowers placed the bulk of his literary output between 1894 and 1912, a total of nearly 100 articles. The rarity and obscurity of this journal, combined with the fact that deciphering Pitman shorthand as employed by Gowers has become a vanishing art, has insured that these articles have remained "buried in obscurity and locked up in code" 1 for nearly a century. We examine the history of Gowers' interest and involvement in shorthand using a complete transliteration of his medical shorthand publications.

Methods. Issues of PRCT were obtained from the Countway Library of Medicine at Harvard Medical School, the National Library of Medicine, the Library of the College of Physicians of Philadelphia (Osler's set), and the collections of the New York Public Library and the Library of the New York Academy of Medicine. A complete set was collected of all shorthand articles by Gowers listed in his bibliography. ${ }^{1}$

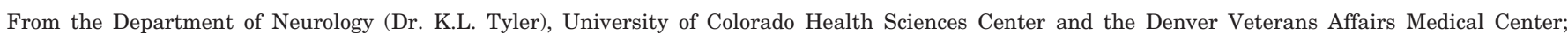
Greeley, CO (D. Roberts); and Department of Neurology, Brigham and Women's Hospital and Harvard Medical School (Dr. H.R.T.), Boston, MA.

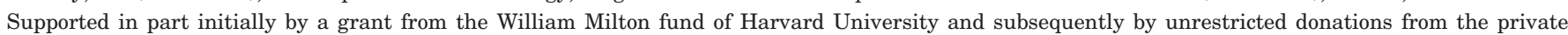
patients of Dr. H. Richard Tyler. K.L.T. is a recipient of the American Academy of Neurology's Lawrence McHenry Jr. Award 2000.

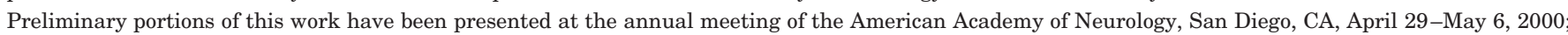
and at the Mansell Bequest Symposium, London, May 18-19, 1998.

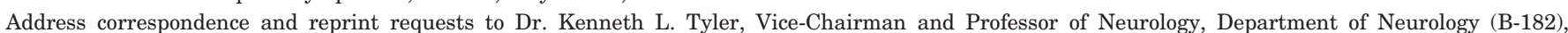

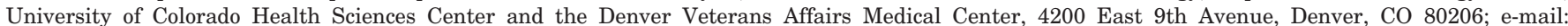
Ken.Tyler@UCHSC.edu 
Shorthand transliterations were performed by Dorothy Roberts, a qualified transcriber of Pitman shorthand. The accuracy of transliterations was verified using the Phonographic Outlines of Medical Terms, With an Appendix. ${ }^{4}$ The sources of transcriptions from $P R C T$ are identified by the year, volume, and pages of the source issue.

Results and discussion. Gowers and shorthand. ${ }^{3,5}$ Gowers recalled that his textbooks from the Christ Church College School (1856-1860) were "studded with shorthand notes." ${ }^{\text {A }}$ As an apprentice to a country surgeon, he kept a personal diary in shorthand, and later, during his 4 years as a medical student at University College Hospital, he took shorthand notes of many of his lectures, stating that "I found no textbook comparable to them." At the bedside he began his lifelong practice of recording shorthand notes of the key details of clinical cases, later indicating "I possess shorthand notes taken by myself of not less than twenty thousand cases of disease; of one kind of disease alone [epilepsy] I have notes of nearly five thousand cases." ${ }^{6}$ MacDonald Critchley speculated that Gowers' casebooks were destroyed in World War II (personal communication, 1985), although some have survived. ${ }^{8}$

In support of the quixotic goal of having shorthand incorporated into the medical curriculum, Gowers stressed the ease with which shorthand could be learned. A student practicing an hour a day could easily learn to take shorthand notes at speeds three times faster than longhand notes, he asserted. ${ }^{6} \mathrm{~A}$ novice could take shorthand notes at 100 words/ minute, and an experienced phonographer, like Gowers, could maintain speeds in excess of 4 words/ second.

In 1889, Gowers organized a voluntary proficiency examination in shorthand for medical students, with the inducement of a substantial cash prize for the best student. The initial examination attracted 11 students, of whom eight passed. A repeat examination the following year was canceled due to insufficient interest. ${ }^{9}$

The Society of Medical Phonographers and the $P R C T$. In 1894, Gowers prepared a trial issue of a small medical periodical published entirely in shorthand. The inaugural issue of PRCT appeared in June of 1894 and contained three articles, including one by Sir William Jenner on glossitis and two by Gowers entitled "The ophthalmoscope in general practice" (PRCT 1894;1-2:6-8) and "The treatment of infantile palsy" (PRCT 1894;1-2:9-16). This issue of $P R C T$ was privately published by Gowers and advertised in both The Lancet and the British Medical Journal. Approximately 120 copies were sold ${ }^{10}$ and $\sim 150$ physicians subscribed. The second issue contained six papers, including part II of Gowers' paper on infantile palsy (PRCT 1894;1-2:41-44) and a paper by James Taylor on alcoholic neuritis.

The first issues of $P R C T$ contained a proposal that a "Society of Medical Phonographers" be formed. By late 1894, nearly 60 individuals agreed to become the founding members of this Society. The First General Meeting was held on July 30, 1895, at which Gowers was elected President (an office later held by Sir David Ferrier). James Taylor, who would assist Gowers with the third edition of his famous Manual of Diseases of the Nervous System and edit Hughlings Jackson's papers, succeeded Gowers as editor of the PRCT.

In Gowers' inaugural address to the Society, ${ }^{5}$ he indicated that its purpose was to promote medical knowledge, facilitate its acquisition, and augment its application through the special means of the application of shorthand. Shorthand facilitated the rapid and immediate recording of observations, especially of rapidly evolving phenomena as they occurred. "Without the use of writing the facts that pass before him [the physician] will leave only a transient furrow in the sands of unaided memory, vanishing for the most part when new facts disturb the surface . . .." Gowers hoped that shared use of shorthand might facilitate mutual support among its practitioners in professional endeavors and activities (PRCT 1896;2: 81-87).

The PRCT appeared on a semi-regular basis between 1894 and 1912, encompassing 17 yearly volumes each with $\sim 9$ issues. The third issue, in 1895, saw the Journal's title amended to the Phonographic Record of Clinical Teaching and Medical Science, to reflect more accurately the interests of the members of the Society and the contents of the journal. The Society also prepared a series of pamphlets on the use of shorthand by students ${ }^{1}$ and medical practitioners, ${ }^{12}$ and one illustrating over 2500 phonographic outlines and their translation. ${ }^{4}$ At least two shorthand books written by Gowers also appeared under the auspices of the Society. ${ }^{13,14}$

Membership in the Society reached nearly 250 by July of $1896,{ }^{10}$ but interest in its activities waned after Gowers was forced by ill health to curtail his active involvement. The Society was dissolved in 1912 , and the last issue of its journal appeared in December 1911.

Gowers papers in PRCT. A complete transcription of all Gowers' publications in this journal has now been completed, comprising nearly 100 articles. None of these papers has been previously transcribed. Together they provide important new insights into Gowers and his work, as well as a novel perspective on his method of neurologic practice. The papers cover a wide range of subjects, but can be grouped into several categories, each of which is discussed briefly.

Problems in Practical Diagnosis. Under the heading "Problems in Practical Diagnosis," Gowers wrote 22 papers (figure 1). Their basic format was quite similar. First, there was a description of the patient's history and pertinent findings on examination. Gowers suggested, "I would strongly recommend the reader, before proceeding further, to consider the facts above given and endeavor to form 


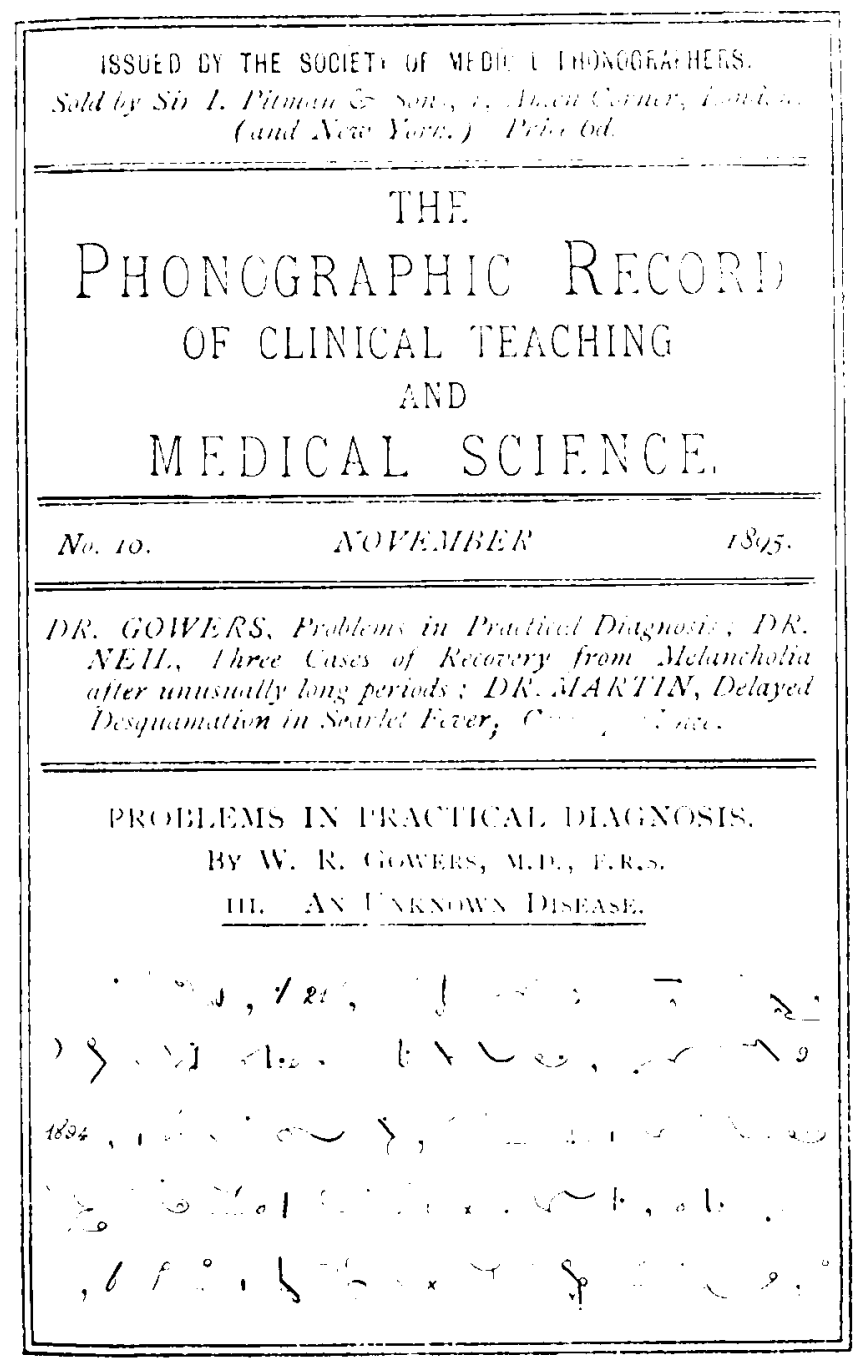

Figure 1. Under the heading "Problems in Practical Diagnosis," Gowers wrote 22 papers.

a diagnosis. Let him do so under the compulsion of being obliged to form and express some opinion. I would then advise him to write down the conclusion and its grounds" (PRCT 1895;1-2:177-182). Each article ended with a discussion of the differential and final diagnoses. Readers were admonished that "A correct diagnosis is practicable from the facts above given, and should be made. If any reader has a difficulty, it will be useful to others if he will send a statement of it to the Editor, that an answer may be given in the next number" (PRCT 1896;2:10-14). These queries were then published under the heading "Questions and Answers."

The topics covered in "Problems in Practical Diagnosis" were diverse. A sampling of several of these articles provides an interesting overview of the general type of material present in the PRCT. They illustrate an aspect of Gowers that is not readily discernible in his more formal lectures and monographs. These problems are case presentations, with Gowers then reviewing the salient features and leading the reader through a differential diagnosis.
In No. 1, "A sudden cerebral lesion" (PRCT 1894; 1-2:121-127), Gowers discussed the importance of the pattern of weakness in differentiating between cerebral and capsular lesions, noting that complete paralysis of the arm with only slight paralysis of the leg is more likely to be found in cortical lesions, whereas capsular lesions generally involve weakness in both arm and leg. He noted that convulsions often indicate a cortical lesion.

Problem No. 4, "Brain, or spinal cord?" (PRCT 1896;2:10-14), provided an opportunity for Gowers to contrast patterns of weakness produced by cerebral and spinal lesions. He noted that lesions involving the anterior horn or the nerves produce rapid muscular wasting and loss of faradic irritability, and he again emphasized that "the leg is scarcely ever paralyzed very much more than the arm by a cerebral lesion ....."

Problem No. 5, "Prognostic diagnosis in sudden hemiplegia" (PRCT 1896;2:70-73), involved a man

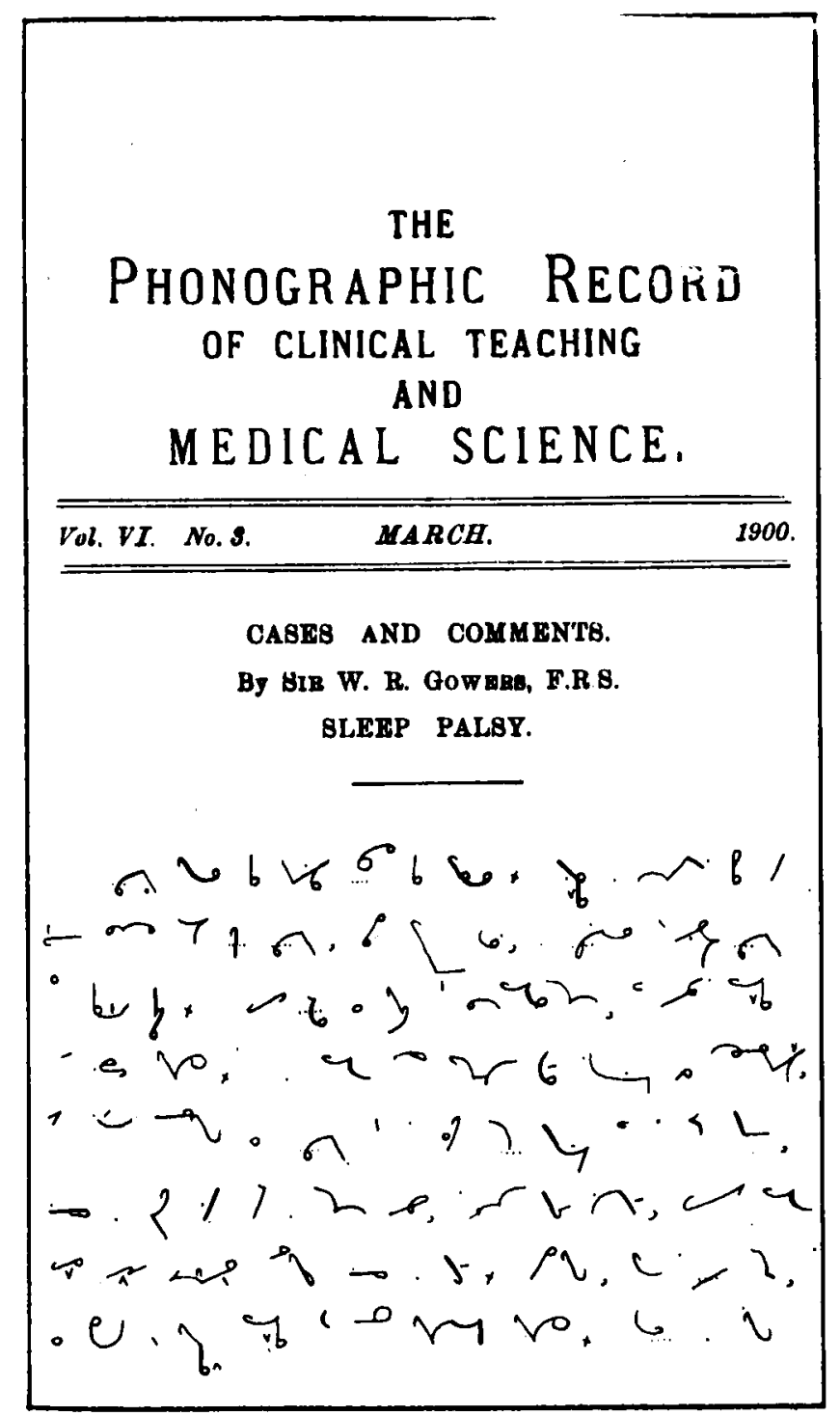

Figure 2. In "Notes on Clinical Teaching" and "Cases and Comments," Gowers covered several topics. 


\section{THE PhONOGRAPHIC RECORD OF CLINICAL TEACHING AND MEDICAL SCIENCE.}

\begin{tabular}{llll} 
Vol. XI. No. 3. JULY. & 1905 \\
\hline
\end{tabular}

\section{A POST-GRadUATE LEOTURE ON ADUL' POLIOMYELITIS.}

By SIR W. R. Gow ERs, M.D., F.R.8.

(Delivered at the National Hospital for the Paralysed and Epileptic, Queen Square, London, on Feb. 12th, 1896.)

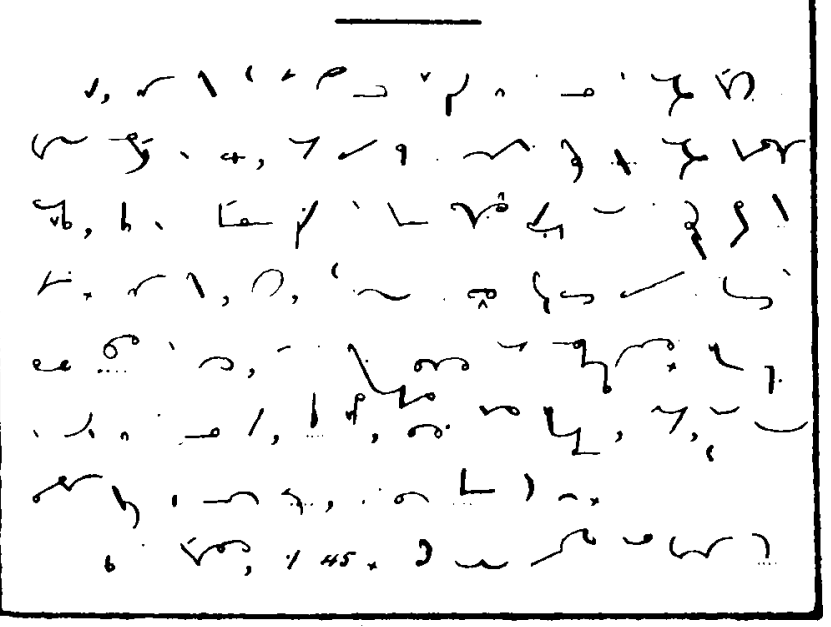

Figure 3. Gowers wrote several articles summarizing lectures he delivered at Queen Square and University College Hospital.

who developed a "complete right hemiplegia and loss of speech with the exception of 'yes' and 'no'." Gowers emphasized the importance of establishing "What was the lesion"-indicating that this should be the practitioner's first thought in cases of this type and is the "all-important practical point." In discussing the differential diagnosis of "atheromatous thrombosis" and hemorrhage, he emphasized the importance of evaluating the general state of the vascular system, including the pulse and the heart. He suggested that the presence of "prodromata" favors thrombosis, and the greater the depth and duration of coma the greater the likelihood of hemorrhage. He emphasized the importance of identifying the site of the lesion, especially as an indicator of prognosis, and provided an extensive discussion of the clinical features of pontine lesions, differentiating the characteristics of lesions in the upper, middle, and lower thirds of the pons. In reviewing lesions in the lower pons, he stated, "A lesion below the middle of the pons causes 'alternate hemiplegia,' paralysis of the face on the opposite side to the limbs." He noted that pontine lesions may "interfere in a peculiar way with the ocular movements," and distinguished these abnormalities from those in cerebral lesions, "in which there is conjugate deviation of the eyes towards the side of the lesion, that is, paralysis of the movement of both eyes towards the side of the paralysis of the limbs." He emphasized the peculiar tendency of lesions in the upper pons to disturb respiration, and suggested that a "hiccupy cough" can be a clue to pontine disease.

In Problem No. 9, "Paroxysmal unconsciousness" (PRCT 1897;3:129-133), he discussed a woman who developed weekly attacks of unconsciousness followed by a postictal state in which "She spoke and did what she was told, which was always to go to bed, but it was in an automatic way, and, although evidently able to see well, she would stumble over a chair if one was in her way. She always at once went to sleep, and awoke without the slightest recollection of anything that had happened ... [Her] state is practically identical with the period of automatic action which is so common after a minor epileptic seizure, in which actions are performed in an apparently conscious manner, but nothing is afterwards remembered regarding them."

Problem No. 13 provided the opportunity to discuss "Cerebellar disease" (PRCT 1899;5:153). "Cases of cerebellar disease furnish some of the most difficult and obscure problems in diagnosis. The symptoms, especially in disease of the hemispheres of the cerebellum, are often extremely slight in proportion to the extent and character of the lesion ...." He described a woman with right supraorbital and occipital headache with pain radiating down the neck associated with vomiting, bilateral optic "neuritis," nystagmus worse on looking to the right, diminished left lateral gaze, head tilt toward the right shoulder, a staggering gait with a tendency to fall to the left and backwards, and incoordination. He concluded that she was "the subject of chronic irritative disease of the left hemisphere of the cerebellum ....," probably either a cerebellar abscess or a tumor. He then noted, "Accordingly the patient was trephined by Mr. Horsley at the left occipital fossa. The dura mater was tense, and on incising it, the hemisphere of the cerebellum bulged out to an extreme degree. On cutting into it a large globular tumor was found, the size of a Tangerine orange . . . the whole tumor shelled out easily. It was found, on subsequent examination, to be a tubercular mass."

Other topics. In addition to the "Problems in Practical Diagnosis," Gowers wrote a variety of other articles. He emphasized the potential value of the $P R C T$ in facilitating "collective investigation." $\mathrm{He}$ suggested that members of the Society collect data on certain predetermined subjects, record the information, and send it by postcard to the secretary of the Society. The results would then be collated and 
published in the PRCT. Examples of collective investigations included studying the relationship between the onset of Sydenham's chorea and the season of the year and studying epileptics "known to have remained free from fits for more than five years after the entire cessation of therapy" (PRCT 1896;2:41,43-45).

Several of Gowers' PRCT papers dealt with therapeutics. He wrote on "The treatment of infantile palsy" (PRCT 1894;1-2:9-16, 31-32, 41-44) and the treatment of syphilis (PRCT 1897;3:102-106 and PRCT 1898;4:65-67). He thought that acute anterior poliomyelitis resulted from an abnormal blood state that produced inflammation in the gray matter of the spinal cord. Inflammation in turn resulted in vascular stasis, local thrombosis, and "the passage of leucocytes through the wall [of the vessel] ... and the infiltration of the tissues by them." In an effort to limit inflammation and its complications he emphasized proper positioning of the recuperating patient, the use of counterirritants, and anti-inflammatory medications such as salicylate of soda or salicin. He thought that "nervine tonics," including strychnine, might prove beneficial after the inflammatory phase subsided. He treated weak muscles with electrical stimulation and massage and described orthotic devices to minimize the effects of imbalanced action of weak muscles.

In, "Notes on Clinical Teaching" and "Cases and Comments" (figure 2), Gowers covered topics including sleep paralysis (PRCT 1900;6:33-36), paralysis agitans and cerebral degeneration (PRCT 1903;9:24$25)$, general paralysis of the insane (PRCT 1909;15: 73-77), alcoholic pseudotabes (PRCT 1909;15:1-3), and facial contracture (PRCT 1909;15:25-28). He also wrote several articles summarizing lectures he delivered at Queen Square and University College Hospital (figure 3) on subjects including chronic myelitis (PRCT 1900;6:105-111), chorea (PRCT 1904; 10:113-122, 129-136), neurosyphilis (PRCT 1905;11: 18-26), adult poliomyelitis (PRCT 1905;11:65-73), intracranial tumors (PRCT 1907;13:83-89), sudden cerebral lesions (PRCT 1907;13:111-118), pseudohypertrophic paralysis (PRCT 1908;14:89-92), and the nervous system in old age (PRCT 1908;14:33-40). In many instances these lectures expanded significantly on topics in his monographs or covered material not found elsewhere (e.g., the nervous system in old age, "the Neurology of the eyelids" [PRCT 1910; 16:6-12]).

\section{Acknowledgement}

Mr. Richard Wolfe, during his tenure as curator of the Countway Library's rare books collection, graciously provided access to many original materials in the library's collection. Help with early transliterations was provided by Mrs. Mary Cowham.

\section{References}

1. Critchley M. Sir William Gowers 1845-1915. London: Heinemann, 1949.

2. Gowers WR. A manual of diseases of the nervous system. London: Churchill, 1886-1888.

3. Tyler KL, Tyler HR. Sir William Richard Gowers (1845-1915): exhumation and decoding of his shorthand publications. In: Rose FC, ed. A short history of neurology. The British contribution 1660-1910. London: Butterworth-Heinemann, 1999.

4. Society of Medical Phonographers. Phonographic outlines of medical terms, with an appendix. 3rd ed. London: Isaac Pitman and Sons, 1902.

5. Gowers WR. The inaugural address on the art of writing in relation to medical and scientific work. Delivered before the Society of Medical Phonographers. BMJ 1895;2:817-819.

6 . Gowers WR. The value of shorthand to the student and practitioner of medicine. Lancet 1887;2:703-704.

7. Gowers WR. Shorthand and students. BMJ 1897;1:113-114.

8. Youl BD. Gowers' shorthand. Lancet 1990;336:1588-1589.

9. Gowers WR. The origin of the Society of Medical Phonographers. Phonographic Record of Clinical Teaching 1894;1(no. 1, June).

10. Gowers WR. Annual address to the members by the president of the society. Phonographic Record of Clinical Teaching 1896; 2:81-87.

11. Gowers WR. The use of shorthand by the student. London: Isaac Pitman and Sons, 1895.

12. Gowers WR. The use of shorthand by the practitioner. London: Isaac Pitman and Sons, 1895.

13. Gowers WR. The work of the life assurance examiner. London: Isaac Pitman and Sons, 1901.

14. Gowers WR. Diagnosis of the nature of organic brain disease [in Pitman shorthand]. London: Isaac Pitman and Sons, 1897. 


\section{Neurology}

\section{The shorthand publications of Sir William Richard Gowers \\ Kenneth L. Tyler, Dorothy Roberts and H. Richard Tyler \\ Neurology 2000;55;289-293 \\ DOI 10.1212/WNL.55.2.289}

\section{This information is current as of July 25, 2000}

\section{Updated Information \& Services}

References

Permissions \& Licensing

Reprints including high resolution figures, can be found at: http://n.neurology.org/content/55/2/289.full

This article cites 4 articles, 2 of which you can access for free at: http://n.neurology.org/content/55/2/289.full\#ref-list-1

Information about reproducing this article in parts (figures,tables) or in its entirety can be found online at: http://www.neurology.org/about/about_the_journal\#permissions

Information about ordering reprints can be found online: http://n.neurology.org/subscribers/advertise

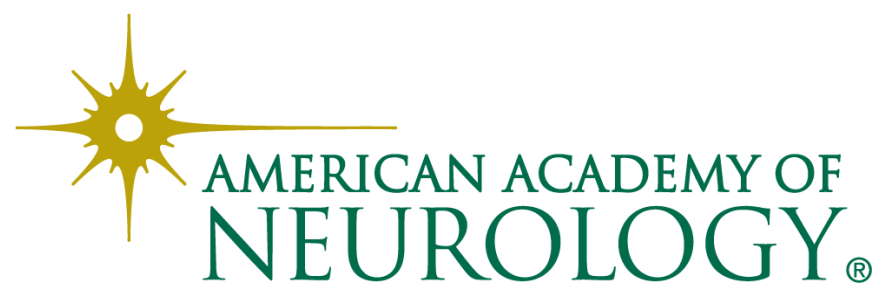

